\title{
Analysis of Local Fracture Driving Force for a Micro-crack under Combined Stress Field in Plastic Zone*
}

\author{
by SHIMIZU Kazuma ${ }^{* *}$, OHATA Mitsuru $^{* *}$, SHOJI Hiroto ${ }^{* *}$, TANIGAWA Hiroyasu ${ }^{* * *}$ and KATO Taichiro ${ }^{* * *}$
}

\begin{abstract}
The critical Weibull stresses for brittle fracture of cracked specimens tested under different loading mode, that is mode I and mixed mode of I and II, estimated with an original Beremin model based on a linear fracture mechanics does not present the unique value. Local fracture driving force to control brittle fracture of a micro-crack in the material under large-scale yielding and combined loading conditions is analyzed based on nonlinear elastic-plastic energy release rate, Local- $J$ of a unit cell containing a penny-shaped crack. Local- $J$ is enlarged due to decrease in normal stress subjected to the horizontal direction with respect to a crack surface under the same normal stress, whereas such stress did not influence the linear elastic energy release rate. Also, the Local- $J$ is significantly enlarged by shear stress acting on the crack plane. These results implied that the local fracture driving force Local- $J$ should be taken into account for estimating the combined loading effect on brittle fracture resistance under large scale yielding condition.
\end{abstract}

Key Words: brittle fracture, large scale yielding, mixed mode, Local approach, elastic-plastic fracture mechanics.

\section{Introduction}

Engineering approach based on conventional fracture mechanics has been used for brittle fracture assessment of structural components. However, many studies have reported that fracture resistance of cracked components subjected to mode I load under large scale yielding condition estimated based on fracture mechanics depends on specimen geometry and size, that is cracktip plastic constraint ${ }^{1-4)}$. Weibull stress as a new fracture parameter based on "Local Approach" has been proposed to evaluate the effect of crack-tip plastic constraint on brittle fracture resistance. The conventional Weibull stress as a facture driving force has been formulated by modeling unstable fracture initiation from pennyshaped micro-cracks in highly stressed field near crack-tip ${ }^{5}$. Under mode I loading condition, many investigations have reported that the critical Weibull stress could be independent of specimen geometry and size, that is crack-tip plastic constraint ${ }^{6-9)}$. However, not only mode I load but also mixed mode load or biaxial load can affect fracture resistance of structural component (e.g., Bass, McAfee, Williams and Pennell ${ }^{10)}$ ). Therefore, it is desirable to establish a unified method to evaluate brittle fracture resistance of cracked components irrespective of plastic constraint and loading modes as well.

As fundamental study for the proposal of the rational fracture parameter for assessment of the cracked component irrespective of plastic constraint and loading mode, the local fracture driving force for micro-crack under combined stress field in plastic zone, which has been employed to the formulation of Weibull stress, was examined by elastic-plastic FE-analysis. Firstly, the loading mode

\footnotetext{
*受付日 2021年5月25日 受理日 2021年9月15日

**正 員 Member, Graduate School of Engineering, Osaka University, 2-1,Yamadaoka, Suita, Osaka, 565-0871, Japan National Institutes for Quantum and Radiological Science and Technology, Rokkasho Fusion Institute, 2-166, ObuchiOmotedate, Rokkasho, Aomori, 039-3212, Japan
}

effect on the critical Weibull stress in accordance with conventional definition employing the linear energy release rate as the local fracture driving force was examined and discussed in terms of the principal stress field around crack-tip of the components. On the basis of the results, a local fracture driving force to control brittle fracture under combined stress field in plastic zone was discussed with focusing on elastic-plastic nonlinear energy release rate, which is named Local- $J$ of a unit cell containing a penny-shaped crack.

\section{Conventional Weibull stress concept}

Conventional Weibull stress as a facture driving force based on the original Beremin model ${ }^{5)}$, which is schematically illustrated in Fig. 1, is given by Eq. (1),

$$
\sigma_{\mathrm{W}}=\left[\frac{1}{V_{0}} \int_{V_{\mathrm{f}}}\left(\sigma_{\mathrm{eff}}\right)^{m} d V_{\mathrm{f}}\right]^{\frac{1}{m}}
$$

where $m$ is material constant that reflects the distribution of microcracks for the material. $V_{0}$ and $V_{\mathrm{f}}$ denote unit volume and volume of high stress field in fracture process zone near crack-tip, respectively. The critical Weibull stress $\sigma_{\mathrm{W}, \mathrm{cr}}$ at brittle fracture initiation obeys the Weibull distribution with two parameter $m$ and $\sigma_{\mathrm{u}}$ as expressed in Eq. (2).

$$
F\left(\sigma_{\mathrm{W}, \mathrm{cr}}\right)=1-\exp \left[-\left(\frac{\sigma_{\mathrm{W}, \mathrm{cr}}}{\sigma_{\mathrm{u}}}\right)^{m}\right]
$$

The Weibull stress has been proposed by modeling fracture initiation from penny-shaped micro-cracks in high stress field near crack-tip. The effective stress $\sigma_{\text {eff }}$ for fracture initiation of the component including micro-cracks is derived from the following concept based on the linear elastic fracture mechanics.

In regard to a penny-shaped micro crack in triaxial stress field, stress intensity factors, $K_{\mathrm{I}}, K_{\mathrm{II}}$ and $K_{\mathrm{III}}$ under mode I, II, and III loading conditions is written in the form of Eq.(3), 


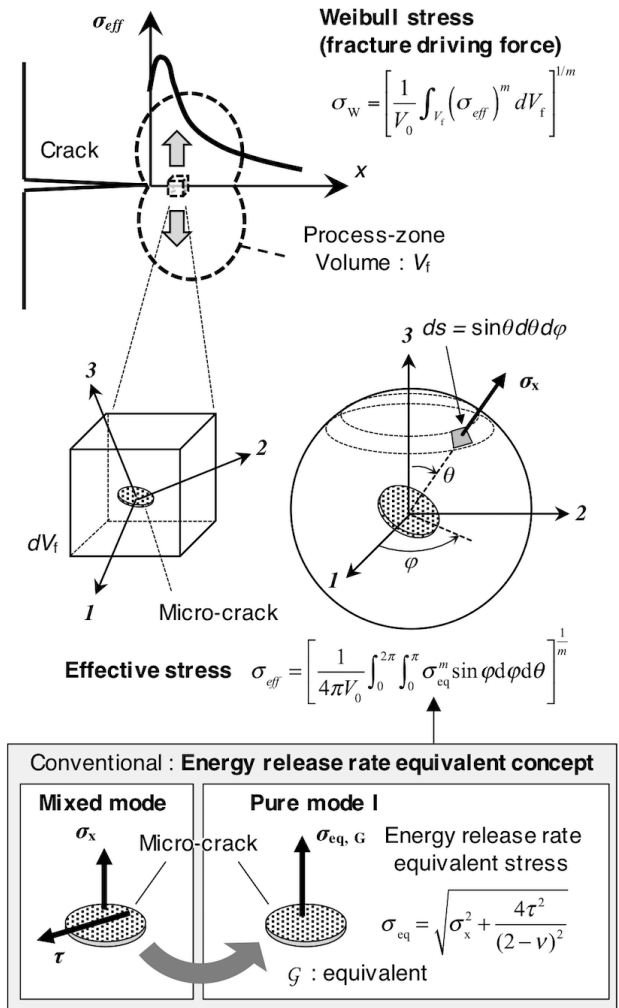

Fig.1 Schematic illustration of Weibull stress concept based on linear energy release rate.

$$
\begin{aligned}
K_{\mathrm{I}} & =2 \sigma_{\times} \sqrt{\frac{a}{\pi}} \\
K_{\mathrm{II}} & =\frac{2}{2-v} \tau \sqrt{\frac{a}{\pi}} \cos \phi \\
K_{\mathrm{III}} & =\frac{4(1-v)}{2-v} \tau \sqrt{\frac{a}{\pi}} \cos \phi
\end{aligned}
$$

where $\sigma_{\mathrm{x}}$ and $\tau$ are normal stress and in-plane maximum shear stress subjected to penny-shaped crack plane. $a$ and $\phi$ denote the radius of penny-shaped crack and the angle from shear stress direction on the crack plane, and $v$ denotes Poisson's ratio, respectively. A total energy release rate $G_{\text {mixed }}$ for the penny-shaped micro crack under mixed mode load can be written as Eq. (4).

$$
\begin{aligned}
G_{\text {mixed }} & =\frac{1-v^{2}}{E}\left(K_{\mathrm{I}}^{2}+K_{\mathrm{II}}^{2}+\frac{1}{1-v} K_{\mathrm{III}}^{2}\right) \\
& =\frac{4 a\left(1-v^{2}\right)}{\pi E}\left\{\sigma_{\mathrm{x}}^{2}+\frac{4}{(2-v)^{2}} \tau^{2}\left[\cos ^{2} \phi+(1-v) \sin ^{2} \phi\right]\right\}
\end{aligned}
$$

Maximum value of $G_{\text {mixed }}$ is given as Eq. (5), where $\phi=0$.

$$
G_{\max }=\frac{4 a\left(1-v^{2}\right)}{\pi E}\left[\sigma_{\mathrm{x}}^{2}+\frac{4}{(2-v)^{2}} \tau^{2}\right]
$$

Therefore, on the basis of the linear elastic fracture mechanics, a fracture controlling stress for a penny-shaped crack under mixed mode loading condition can be written as Eq.(6). This stress is called "energy release rate equivalent stress" $\sigma_{\text {eq }}$, which is equivalent to the stress under mode I loading condition as expressed in Eq. (7).

$$
\begin{gathered}
\sigma_{\mathrm{eq}}=\sqrt{\sigma_{\mathrm{x}}^{2}+\frac{4}{(2-v)^{2}} \tau^{2}} \\
G_{\mathrm{I}, \mathrm{eq}}=\frac{4 a\left(1-v^{2}\right)}{\pi E} \sigma_{\mathrm{eq}}^{2}
\end{gathered}
$$

Since the micro-cracks are distributed with random orientation in the stress field, effective stress to fracture of unit volume including a micro-crack is calculated by integrating equivalent stress on each orientation as expressed in Eq. (8),

$$
\sigma_{\text {eff }}=\left[\frac{1}{4 \pi V_{0}} \int_{0}^{2 \pi} \int_{0}^{\pi}\left(\sigma_{\mathrm{eq}}\right)^{m} \sin \theta d \theta d \varphi\right]^{\frac{1}{m}}
$$

where $V_{0}$ denotes reference volume and the angle $\varphi$ and $\theta$ define orientation of a micro-crack relative to the principal stress axis (see Fig. 1).

Many investigations have been reported that the critical Weibull stress derived on the basis of the original Beremin model could be independent of specimen geometry and size, that is crack-tip plastic constraint under mode I loading ${ }^{6-9)}$. The concept of the Weibull stress is incorporated to a part of standard method for brittle fracture assessment taking account of plastic constraint effect ${ }^{11)}$.

\section{Analysis of fracture resistance under mixed mode load based on conventional Weibull stress concept}

This section discusses about applicability of the conventional Weibull stress criterion for assessment of loading mode effect on cleavage fracture resistance. Then, fracture tests for a structural steel under mode I and mixed mode loading conditions are conducted, and critical Weibull stresses for the specimens under both loading conditions are calculated and compared with each other. The non-uniqueness of the critical Weibull stress is demonstrated, so that non-applicability of the conventional Weibull stress criterion is discussed in terms of the difference in crack-tip stress fields of both specimens.

\subsection{Material and specimens used for fracture test}

Fracture tests were conducted under mode I loading condition and mixed mode loading condition. The details of the following tests can be referred to the previous paper by the present authors ${ }^{12)}$. The steel used for the tests was F82H steel, which was a ferritic steel. 3PB (3-point bend) test was performed at $-120^{\circ} \mathrm{C}$ to obtain fracture resistance under mode I loading condition, which is standard fracture toughness testing. Two types of 3PB specimen with different fatigue pre-crack depth (the ratio of pre-crack depth 
to specimen width, $a_{0} / W=0.5$ and 0.2 ), which could have different plastic constraint, were used. The critical CTOD for 3PB test was calculated according to the ISO $12135(2002)^{13)}$. The geometry of the 3PB specimen was $B=15 \mathrm{~mm}$ (specimen thickness) $\times W=30 \mathrm{~mm}$ (specimen width). On the other hand, 4PS (4-point shear) test under mixed mode loading condition was performed at the same temperature of $-120^{\circ} \mathrm{C}$ as that of the $3 \mathrm{~PB}$ test, and the critical load was obtained. The loading mode ratio of mode I to mode II in the 4PS test is 0.51 . The geometry of the 4PS specimen was $B=15 \mathrm{~mm}$ (specimen thickness) $\times W=15 \mathrm{~mm}$ (specimen width), which is the same thickness as the 3PS specimen. The ratio of pre-crack depth including fatigue pre-crack to specimen width, $a_{0} / W$ is 0.5 .

As the results of $3 \mathrm{~PB}$ test, all specimens fractured in a cleavage manner without ductile crack growth larger than $0.2 \mathrm{~mm}$. The critical CTOD obtained by 3PB test (Mode I test) depended on crack depth, that was crack-tip plastic constraint as many study have been reported. In the $4 \mathrm{~PB}$ testing, the fatigue pre-crack blunted unsymmetrically and propagated to upper inner load-point slantingly. However, cleavage fracture occurred directly from the stretched zone without any ductile crack growth. The brittle fracture resistance in the plastic zone with a large amount of plastic strain was obtained from the 4PS test as well as the 3PB test.

\subsection{Assessment of fracture resistance based on conventional Weibull stress concept}

Fracture resistances for the $3 \mathrm{~PB}$ and the 4PS test were estimated on the basis of the conventional Weibull stress concept.

\subsubsection{FE-analysis of fracture test}

The following FE-analysis used for calculating Weibull stress are same as the previous paper by the present authors ${ }^{12)}$. The FEanalysis was conducted by using the 3-dimentional FE-code, Abaqus ver.6.12. Because of symmetry, one quarter of the 3PB test specimen and one half of the 4PS test specimen used for experiments were modeled. The 8-node isoparametric solid elements with 8-Gaussian points were used in the 3D-model. The minimum element size around the crack tip was $0.03 \mathrm{~mm} \mathrm{x}$ $0.03 \mathrm{~mm}$ in plane. Mechanical properties used for FE-analysis were obtained from round-bar tensile (RBT) specimens tested at $-120^{\circ} \mathrm{C}$, which is the same temperature as the fracture testing condition.

\subsubsection{Estimation of critical Weibull stress}

The conventional Weibull stress expressed in Eq.(1) was calculated by integrating the effective stress $\sigma_{\text {eff }}$ given in Eq. (6). Fracture process zone $V_{\mathrm{f}}$ was limited to the near crack-tip stress field, where the maximum principal stress $\sigma_{1}$ exceeded $1625 \mathrm{MPa}$ corresponding to peak $\sigma_{1}$ ahead of crack-tip at minimum toughness level $\left(K=20 \mathrm{MPa} \sqrt{\mathrm{m}}\right.$, shown in ASTM E1921 $\left.{ }^{14)}\right)$. At first step, a critical Weibull stress distribution of the steel was identified from the $3 \mathrm{~PB}$ test results. Whereas there exist several methods for identification of the critical Weibull stress distribution proposed in this research fields, the method originally proposed by Gao, Ruggieri, and Dodds ${ }^{15)}$ was referred. This method uses 2 types of specimen with different crack depth, which can uniquely identify the material parameters $m$ and $\sigma_{\mathrm{u}}$. As shown in Fig. 2, the critical Weibull stress distribution was determined and the Weibull shape parameter $m$ was identified to be 2.6. At the same time, it can be recognized that the parameter $m$ in 2.6 is material constant independent of at least the plastic constraint under mode I load.

Then, by using the parameter $m$ in 2.6, critical Weibull stresses for 4PS specimen (Mixed mode load) were calculated. As compared in Fig. 2, critical Weibull stress distribution for 4PS specimen was significantly different from the ones obtained by $3 \mathrm{~PB}$ test results. As shown in Fig. 3, the critical load at fracture probability $F=20.6 \%$ for 4PS specimen predicted from the critical Weibull stress distribution under mode I load exhibited much larger value than the experimental results. Consequently, critical Weibull stress estimated in accordance with the conventional definition was found not to be identical independent of the loading modes.

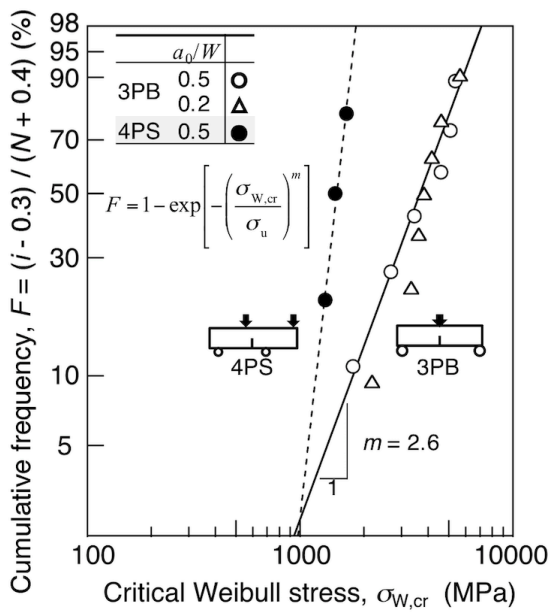

Fig. 2 Comparison between critical Weibull stress distributions for 3PB and 4PS specimens.

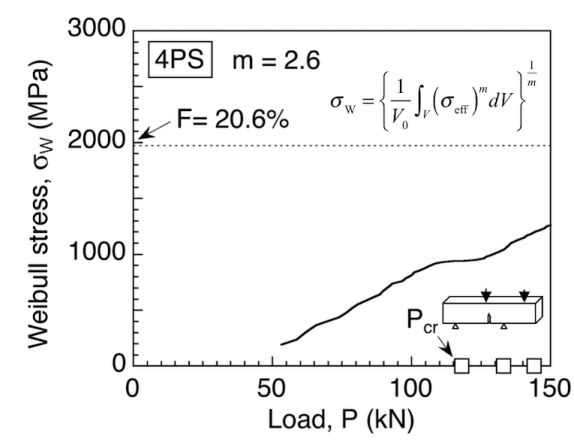

Fig. 3 Prediction of critical load for 4PS specimen by using critical Weibull stress at fracture probability $F=20.6 \%$ for 3PB specimens. 


\subsection{Analysis of crack-tip stress field}

In order to discuss the reason why the critical Weibull stress could depend on the loading mode, the stress fields ahead of the crack-tip were analyzed for both specimens. Fig. 4 shows the distributions of maximum principal stress ahead of the crack-tip at mid-thickness at the same fracture probability $(F=20.6 \%)$ for the 3PB specimen $\left(a_{0} / W=0.5\right.$ and 0.2$)$ and the 4PS specimen $\left(a_{0} / W=0.5\right)$. The 3PB specimen presents almost the same maximum principal stress near the crack-tip regardless of crack depth $\left(a_{0} / W=0.5\right.$ and 0.2$)$. On the other hand, the 4PS specimen presents lower maximum principal stress near crack-tip than the 3PS specimens. These results indicate that the fracture resistance of the components under various loading mode could not be necessarily controlled by the maximum principal stress.

Fig. 5 compares the ratio of middle principal stress and minimum principal stress normalized by maximum principal stress $\left(\sigma_{2} / \sigma_{1}\right.$ and $\left.\sigma_{3} / \sigma_{1}\right)$ for the $3 \mathrm{~PB}$ specimen $\left(a_{0} / W=0.5\right.$ and 0.2$)$ and the 4PS specimen. The $3 \mathrm{~PB}$ specimens present almost the same distributions of $\sigma_{2} / \sigma_{1}$ and $\sigma_{3} / \sigma_{1}$ regardless of crack depth $\left(a_{0} / W=0.5\right.$ and 0.2$)$. On the other hands, the 4PS specimen presents different maximum principal stress distributions from $3 \mathrm{~PB}$ tests, that was the significant lower distribution of $\sigma_{3} / \sigma_{1}$ than the $3 \mathrm{~PB}$ specimens. These results indicate that the mixed mode load provides the different combined stress field around crack-tip from that under mode I load.

Therefore, the reason why the conventional Weibull stress could not be a unified fracture controlling parameter was found to be that the energy release rate equivalent stress (Eq.(6)) could not consider the effect of different combined stress field on brittle fracture resistance.

\section{Analysis of local fracture driving force under combined stress field in plastic zone}

One of the reasons for the non-applicability of conventional Weibull stress concept under combined stress field could be employment of the energy release rate equivalent stress (Eq. (6))

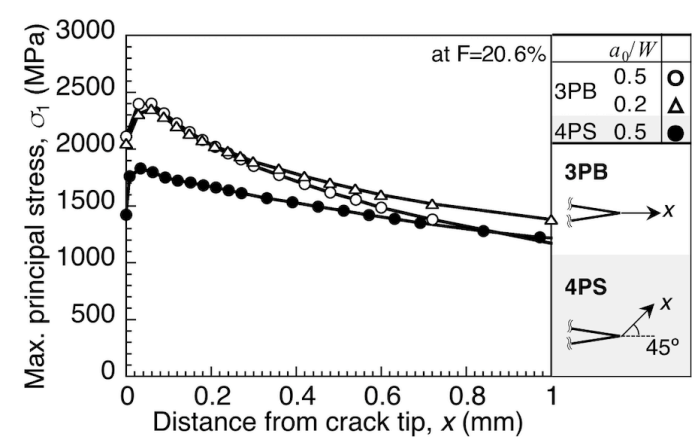

Fig. 4 Comparison between maximum principal stress distributions near crack tip for 3PB $\left(a_{0} / W=0.5,0.2\right)$ and 4PS specimens at the same fracture probability $(F=20.6 \%)$. based on the linear energy release rate, which would no longer applicable as a local fracture driving force in plastic zone. Then, with the aim of proposing new fracture model, the characteristics of an elastic-plastic local fracture driving force for a penny-shaped micro-crack in plastic zone was analyzed taking account of the combined stress field.

\subsection{FE-analysis of elastic-plastic energy release rate for penny-shaped crack}

In order to investigate the effect of combined stress on elasticplastic local fracture driving force in plastic zone, $J$-integral as nonlinear energy release rate for a unit cell including micro-crack was calculated under the following conditions "Case 1" and "Case 2" as shown in Fig. 6.

In the Case 1 , effect of normal stress $\sigma_{\mathrm{y}}$ and $\sigma_{\mathrm{z}}$, acting in transverse direction of normal stress $\sigma_{\mathrm{x}}$ that is applied to the

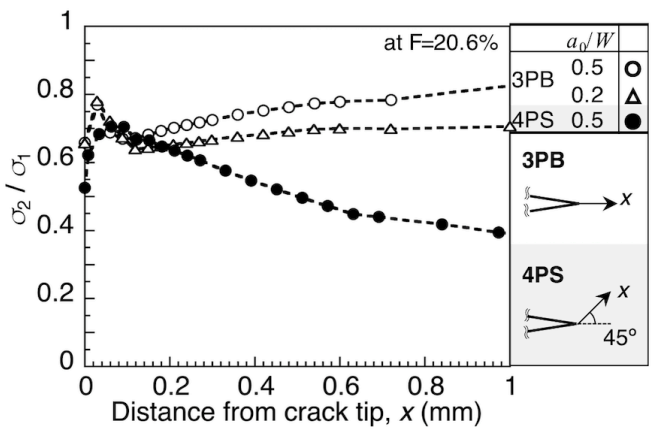

(a) $\sigma_{2} / \sigma_{1}$ distribution

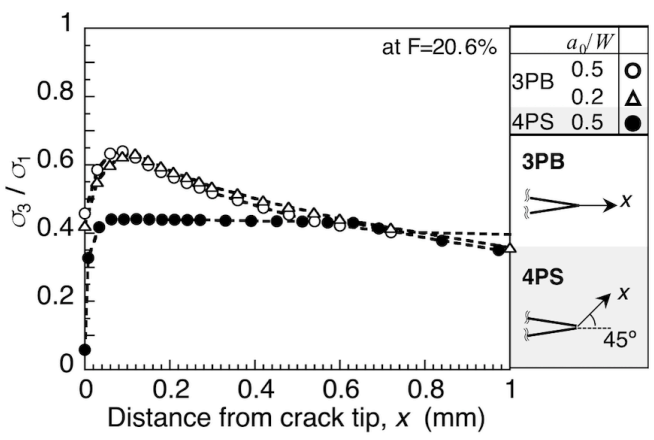

(b) $\sigma_{3} / \sigma_{1}$ distribution

Fig. 5 Comparison between maximum principal stress ratios for $3 \mathrm{~PB}$ specimens with different $a_{0} / W$ and 4PS specimen.

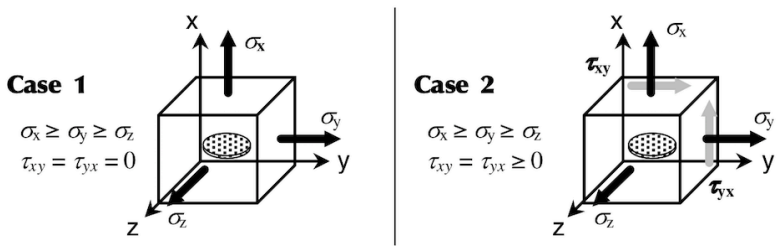

Fig. 6 Schematic illustration of unit cell including penny-shaped crack under combined loading condition. 
normal direction of crack surface, on $J$-integral is discussed. In this case, only the normal stress $\left(\sigma_{\mathrm{x}}, \sigma_{\mathrm{y}}, \sigma_{\mathrm{z}}\right)$ is subjected to the unit cell, which corresponds to principal stress. And in the Case 2, effect of shear stress $\left(\tau_{\mathrm{xy}}=\tau_{\mathrm{yx}}\right)$ subjected to the crack plane on $J$-integral is discussed, where the normal stresses $\left(\sigma_{\mathrm{x}}, \sigma_{\mathrm{y}}, \sigma_{\mathrm{z}}\right)$ were also applied.

Then, two types of FE-model, which were cubic unit cells including a penny-shaped crack in the middle of the model, were used for the analysis as shown in Fig. 7. One is a " $0{ }^{\circ}$-model", where the crack plane is normal to the normal stress $\sigma_{\mathrm{x}}$ (maximum principal stress). The other is a " $45^{\circ}$-model", where the crack plane is tilted $45^{\circ}$ to the axis of maximum principal stress. In both models, the size of the penny-shaped crack was set to be enough small compared with the unit cell size so that deformation of the crack did not influence global deformation (ratio of diameter of the crack to size of the unit cell is around 0.1 ). In each model, two types of a penny-shaped crack in the unit cell, where the radius a was $1 \mathrm{~mm}$ and $0.95 \mathrm{~mm}$, was assumed. Due to symmetry, one half of the unit cell was modeled. The elastic-plastic FE-analysis was conducted by using the 3-dimentional FE-code, Abaqus ver.6.12. The elements used were 8-node isoparametric elements with 8 -Gaussian points.

Combined stress conditions applied to penny-shaped crack and corresponding boundary conditions for FE-analysis of the $0^{\circ}$-model and the $45^{\circ}$-model are summarized in Fig. 8 and Table 1.

In this study, $J$-integral that was nonlinear energy release rate of a unit cell including a micro-crack was defined as external work needed to propagate a crack by unit area, where it was confirmed to be almost consistent with an average of path-independent $J$-integral around the crack front (see Appendix). Therefore, such defined $J$-integral, which was named "Local- $J$ " in this paper, for the unit cell was calculated in accordance with the following procedure Step I to III as illustrated in Fig. 9.

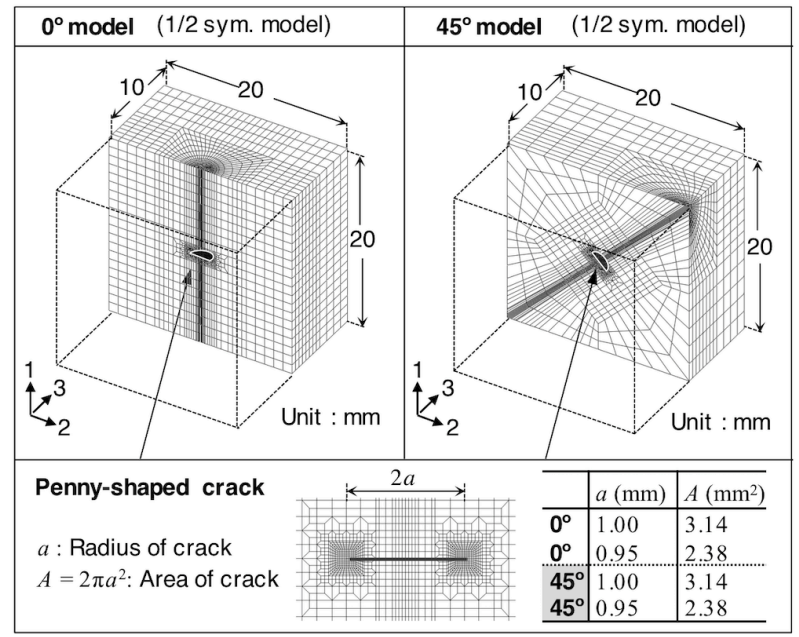

Fig. 7 Mesh division of unit cell models including penny-shaped crack
Step I Two FE-models with different area $A$ and $A+\Delta A$ of penny-shaped cracks are subjected to the same combined load.

Step II Differences in complementary energy in each direction 1, 2 and 3 axis $\left(\Delta \Pi_{i}^{*}\right)$, whose summations are external work needed to propagate a crack by $\Delta A$ are calculated from FE-analytical results.

Step III "Local- $J$ " as external work needed to propagate a unit area of a crack can be obtained by Eq. (9).

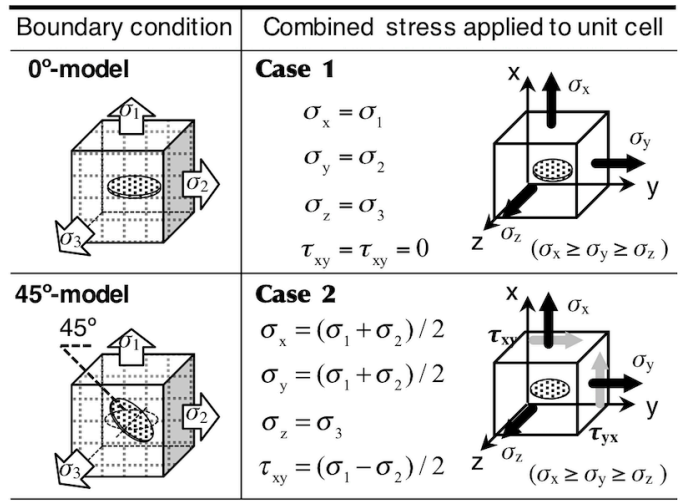

Fig. 8 Schematic illustration of method to calculate Local- $J$ by using unit cell model including penny-shaped crack.

Table 1 Combined stress conditions applied to penny-shaped crack.

\begin{tabular}{|c|c|c|c|}
\hline \multicolumn{2}{|c|}{ Conditions } & penny-shaped crack & $\begin{array}{c}\text { FE-model } \\
\left.0^{\circ} \text { or } 45^{\circ}\right) \sigma_{1}: \sigma_{2}: \sigma_{3}\end{array}$ \\
\hline \multirow{4}{*}{ Case 1} & 1-1 & $1: \mathbf{0 . 0 0}: \mathbf{0 . 0 0}: 0.00$ & $\left(0^{\circ}\right) 1: 0.00: 0.00$ \\
\hline & 1-2 & $1: \mathbf{0 . 5 0}: \mathbf{0 . 5 0}: 0.00$ & $\left(0^{\circ}\right) 1: 0.50: 0.50$ \\
\hline & 1-3 & $1: \mathbf{0 . 6 7}: \mathbf{0 . 6 7}: 0.00$ & $\left(0^{\circ}\right) 1: 0.67: 0.67$ \\
\hline & $1-4$ & $1: \mathbf{0 . 7 5}: \mathbf{0 . 7 5}: 0.00$ & $\left(0^{\circ}\right) 1: 0.75: 0.75$ \\
\hline \multirow{2}{*}{ Case 2} & 2-1 & $1: 1.00: 0.33: \mathbf{0 . 0 0}$ & $\left(0^{\circ}\right) 1: 1.00: 0.33$ \\
\hline & $2-2$ & $1: 1.00: 0.33: \mathbf{0 . 3 3}$ & $\left(45^{\circ}\right) 1: 0.50: 0.25$ \\
\hline
\end{tabular}
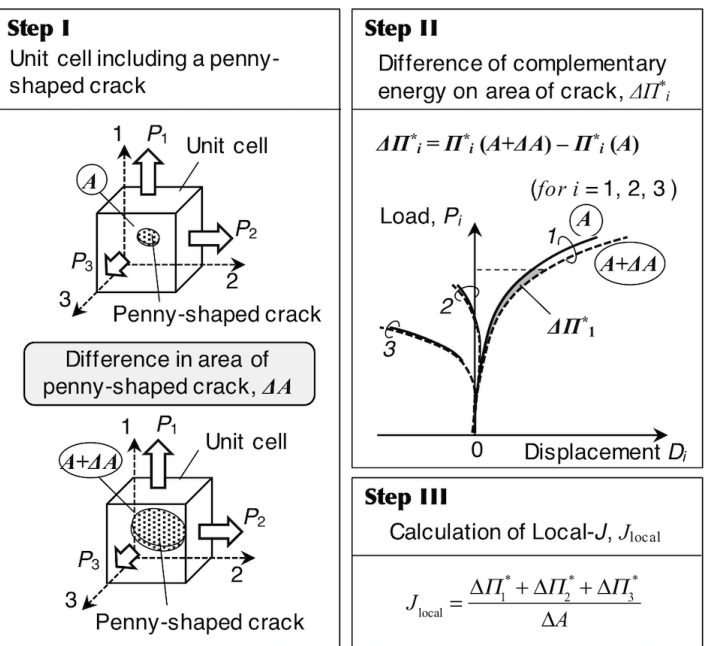

Fig. 9 Schematic illustration of method to calculate Local- $J$ by using unit cell model including penny-shaped crack. 


$$
J_{\text {local }}=\sum_{i=1,2,3} \frac{\Delta \Pi^{*}}{\Delta A}
$$

For comparison, linear elastic energy release rate $G$ of the unit cell was also calculated in the same way by conducting elastic FEanalysis.

The yielding condition in the FE-analysis followed von Mises yield criterion for isotropic hardening materials. Fig. 10 gives equivalent stress - equivalent plastic strain curve used for the elastic-plastic FE-analysis, where a Ramberg-Osgood-type work hardening equation expressed in Eq. (10),

$$
\frac{e}{e_{0}}=\frac{s}{\sigma_{0.2}}+\alpha\left(\frac{s}{\sigma_{0.2}}\right)^{n}
$$

where $e$ and $s$ denote true strain and stress and $e_{0}$ is true strain at $s=\sigma_{0.2}$ and work hardening constant $n=10(0.2 \%$ proof stress $\sigma_{0.2}=500 \mathrm{MPa}$ ) is assumed. The mechanical properties used for the analysis are summarized in Table 2.

In this analysis, combined stress was subjected to the unit cell in the range where global equivalent plastic strain was less than $\bar{\varepsilon}_{\mathrm{p}}=5 \%$. This plastic strain level almost corresponds to the value ahead of the crack-tip for cracked component such as $3 \mathrm{~PB}$ specimen where maximum principal stress exhibits peak value.

\subsection{Effect of combined stress on linear energy release rate and Local- $J$ as nonlinear energy release rate for unit cell}

Analytical results for the Case 1 are given in Fig. 11. Elastic and elastic-plastic energy release rate, $G$ and Local- $J, J_{\text {local }}$ under

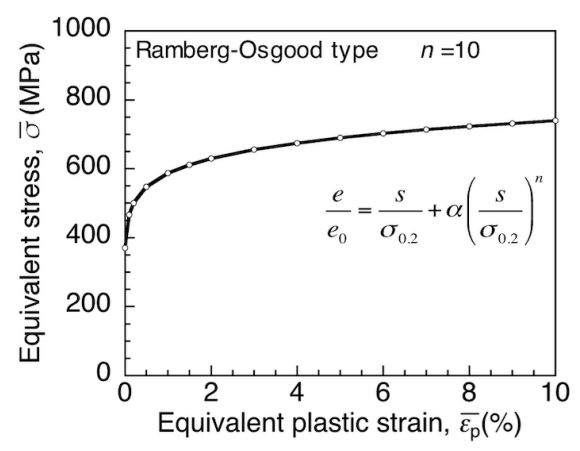

Fig. 10 Equivalent stress - equivalent plastic strain curve used for FE-analysis of unit-cell model.

Table 2 Mechanical properties used for FE-analysis of unit-cell model.

\begin{tabular}{ccc|ccc}
\hline$n$ & $\alpha$ & $\sigma_{0.2}(\mathrm{MPa})$ & $\sigma_{\mathrm{T}}(\mathrm{MPa})$ & $\mathrm{YR}(\%)$ & $\varepsilon_{\mathrm{T}}(\%)$ \\
\hline 10 & 0.82 & 500 & 667 & 0.75 & 10.9 \\
\hline
\end{tabular}

$n$ and $\alpha$ : Ramberg-Osgood type work hardening constant, $\sigma_{0.2}: 0.2 \%$ Proof stress, $\sigma_{\mathrm{T}}$ : Tensile strength,

YR : Yield-to-tensile ratio, $\varepsilon_{\mathrm{T}}$ : Uniform elongation. different combined normal stress ratio were presented as a function of the applied normal stress $\sigma_{\mathrm{x}}$. Regardless of $\sigma_{\mathrm{y}}\left(=\sigma_{\mathrm{z}}\right), G$ showed a unique curve. On the other hand, Local- $J$ is influenced by the normal stress $\sigma_{\mathrm{y}}\left(=\sigma_{\mathrm{z}}\right)$, and the decrease in the ratio of $\sigma_{\mathrm{y}}\left(=\sigma_{\mathrm{z}}\right)$ to $\sigma_{\mathrm{x}}$ enlarges the Local- $J$. Thus, the results indicate that the local fracture driving force based on Local- $J$ could be enlarged due to decrease in normal stress subjected to the parallel direction with respect to a crack surface under the constant normal stress $\sigma_{\mathrm{x}}$, whereas such stress did not influence the linear energy release rate as conventional local fracture driving force.

Fig. 12 discusses the issue of Case 2, that is the effect of shear stress acting on crack plane on $G$ and Local- $J$. Both linear energy release rate $G$ and Local- $J, J_{\text {local }}$ was found to be enlarged due to existence of shear stress. However, linear energy release rate $G_{\mathrm{s}}$ for the unit cell with shear stress is slightly larger than $G_{\mathrm{n}}$ without shear stress at the same maximum normal stress $\sigma_{\mathrm{x}}$. On the other hand, as for the Local- $J, J_{\mathrm{s}}$ for the unit cell with shear stress exhibited significantly larger value compared to $J_{\mathrm{n}}$ without shear stress. Fig. 13 compares the rate of increase in linear energy release rate $\left(G_{\mathrm{s}} / G_{\mathrm{n}}\right)$ with that in Local- $J\left(J_{\mathrm{s}} / J_{\mathrm{n}}\right)$. It was found that $J_{\mathrm{s}} / J_{\mathrm{n}}$ became significantly larger than $G_{\mathrm{s}} / G_{\mathrm{n}}$ above a certain applied normal stress $\sigma_{\mathrm{x}}$ level. And the $J_{\mathrm{s}} / J_{\mathrm{n}}$ continued to increase as increasing applied normal stress $\sigma_{\mathrm{x}}$, whereas $G_{\mathrm{s}} / G_{\mathrm{n}}$ was constant

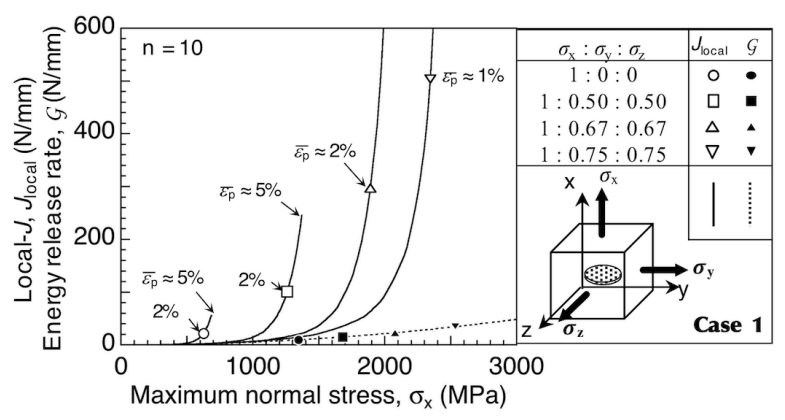

Fig. 11 Effect of normal stress subjected to the horizontal direction on crack surface on $G$ and Local- $J$, $J_{\text {local }}$.

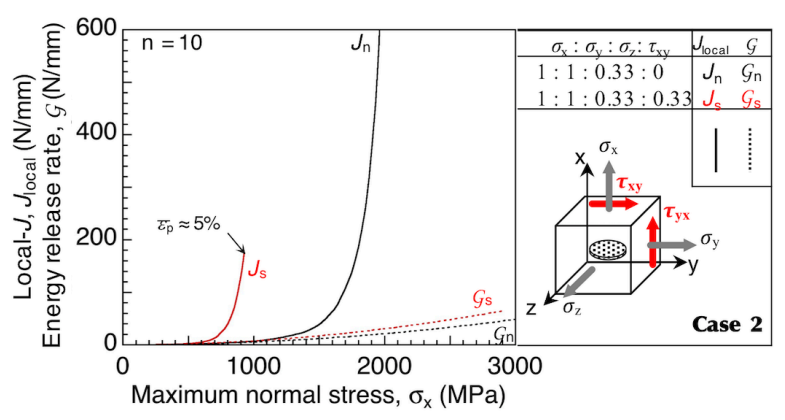

Fig. 12 Effect of shear stress subjected to the crack plane on $G$ and Local- $J$, $J_{\text {local }}$ 


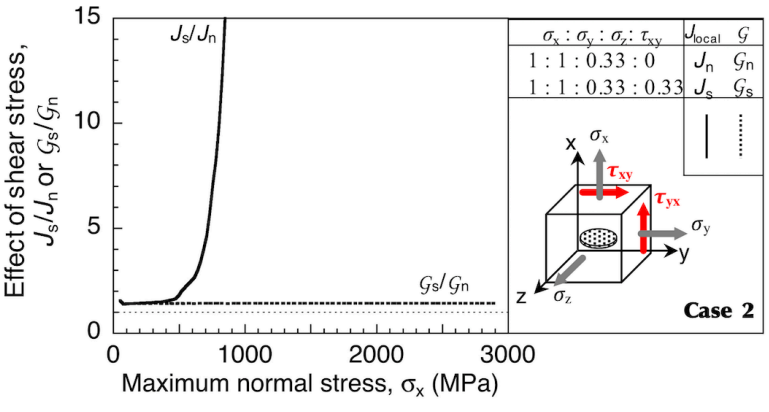

Fig. 13 Difference in rate of increase in $\left(G_{\mathrm{s}} / G_{\mathrm{n}}\right)$ and that in $\left(J_{\mathrm{s}} / J_{\mathrm{n}}\right)$.

regardless of applied normal stress $\sigma_{\mathrm{x}}$. Accordingly, shear stress provided larger effect on Local- $J$ than $G$.

Consequently from these results, local fracture driving force that was Local- $J$ for the unit cell including a penny-shaped crack under elastic-plastic conditions found to be enlarged due to lower principal stress ratio $\sigma_{2} / \sigma_{1}$ and $\sigma_{3} / \sigma_{1}$ as well as shear stress acting on the crack plane. Namely, referring to the results of the above mentioned analyses (Figs. 4 and 5), it was indicated that the global fracture driving force, that might be proposed through the Local- $J$ based equivalent stress (see Eq.(6)), could be independent of loading mode.

\section{Conclusion}

Applicability of the conventional Weibull stress for assessment of loading mode effect on cleavage fracture resistance was discussed. Critical Weibull stress distribution for 4PS specimen under mixed mode loading conditions was significantly different from the ones obtained by $3 \mathrm{~PB}$ test under mode I loading condition. And mixed mode load provided the different combined stress field around crack-tip from that for mode I load. The reason why the conventional Weibull stress was not a unified fracture controlling parameter could be that the linear fracture mechanics concept, which would no longer applicable under large scale yielding, could not consider the effect of different combined stress field on brittle fracture resistance. Then, the characteristics of an elastic-plastic local fracture driving force for a penny-shaped micro-crack in plastic zone was analyzed taking account of the combined stress field. The local fracture driving force based on Local- $J$ could be enlarged due to decrease in normal stress subjected to the horizontal direction with respect to a crack surface under the same normal stress, whereas such stress did not influence the conventional equivalent stress based on linear energy release rate. Also, the Local- $J$ found to be enlarged significantly by shear stress acting on the crack plane. These results implied that the local fracture driving force Local- $J$ should be taken into account for developing a unified fracture controlling parameter independent of plastic constraint and loading modes.

\section{Annex}

In this study, $J$-integral that is nonlinear energy release rate of a unit cell including a micro-crack was defined as external work needed to propagate a crack by unit area, which is named Local- $J$. The theoretical consistency of this definition has been ensured from the following demonstrations;

1) Stress singularity, that is $J$-controlled stress fields, in the unit cell model including a penny-shaped crack subjected to uniaxial tensile stress $\left(\sigma_{\mathrm{x}}: \sigma_{\mathrm{y}}: \sigma_{\mathrm{z}}=1: 0: 0\right)$ is confirmed to be existence in the range of applied plastic strain level of concern as shown in Fig. A.1.

2) The path independence of $J$-integral estimated by line integral for the unit cell model has been confirmed. Figure A. 2 shows an example of the line integral for many paths around crack-tip of the model under uniaxial tension load. Except paths very close to the crack-tip, $J$-integral is confirmed to be path-independent.

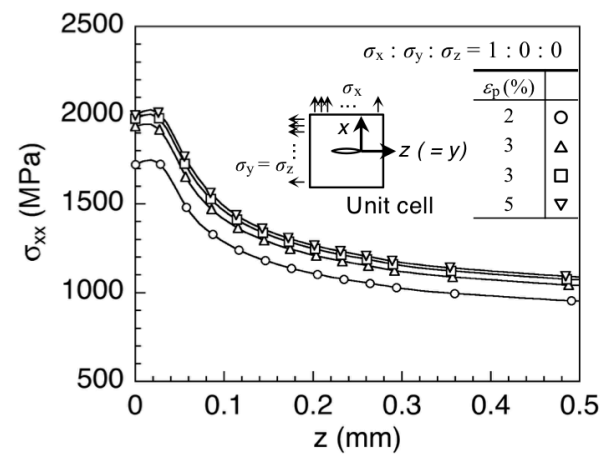

(a) Local stress $\sigma_{\mathrm{xx}}$ distribution near crack tip.

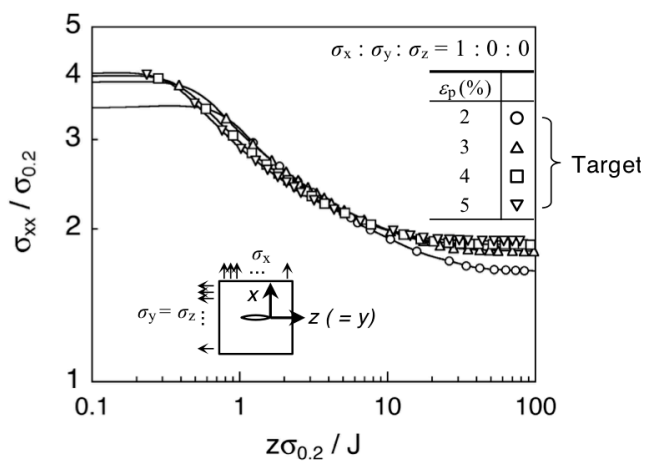

(b) HRR singular stress field near crack tip.

Fig. A.1 Distributions of crack opening stress, $\sigma_{\mathrm{xx}}$ ahead of penny shaped crack-tip in the unit cell subjected to uniaxial tensile stress up to equivalent plastic strain below $\bar{\varepsilon}_{\mathrm{p}}=5 \%$. 


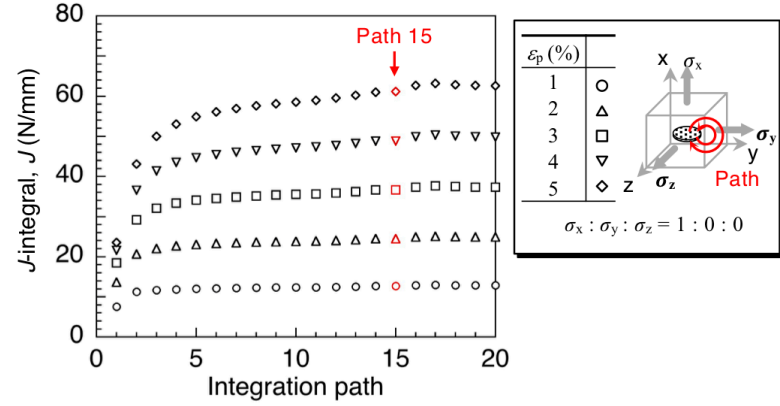

Fig. A.2 $J$-integral obtained from FE-analysis by using line-integral method for the unit cell model.

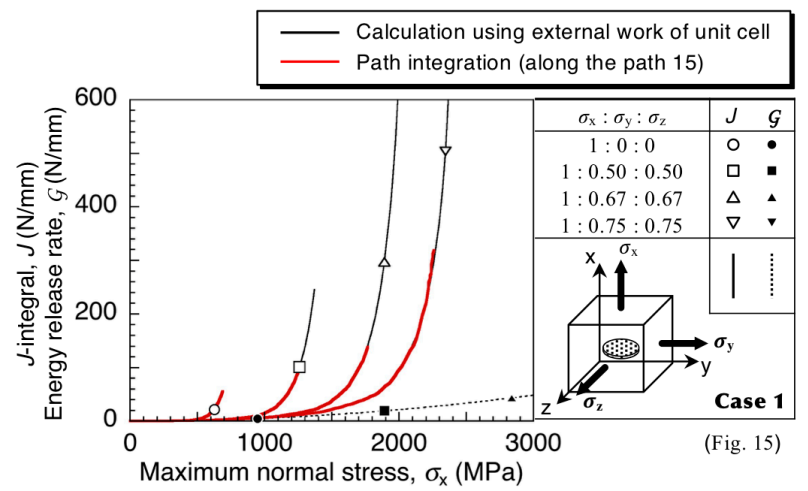

Fig. A.3 Comparison between Local- $J$ defined in this study and pathindependent $J$-integral for the unit cell subjected to axisymmetrical stress.

Furthermore, it is confirmed that the Local- $J$ employed in this study is consistent with the path-independent $J$-integral (referred to Path 15 in Fig. A.2) for the unit cell subjected to axi-symmetrical stress as shown in Fig. A.3.

3) Applicability of the Local- $J$ that is calculated under the assumption of similarity expansion of penny-shaped crack as an average $J$-integral around the crack front in the unit cell subjected to general stress field is confirmed. Fig. A.4 shows one example of the path-independent $J$-integral around crack front for the unit cell under unsymmetrical stress condition. As shown in Fig. A.5, the average of this $J$-integral along crack front is recognized to be almost consistent with Local- $J$ employed in this study. Then, the definition of Local- $J$ used in this study is decided to adopt from engineering point of view, because mesh division to calculate pathindependent $J$-integral for the unit cell under various combined applied stress conditions is very complicated.

\section{References}

1) M. Toyoda, F. Minami, C. Ruggieri, K. Bessyo, K. Arimochi and S.

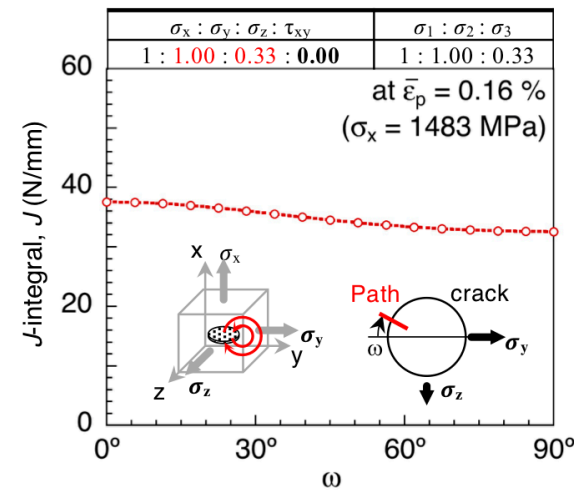

Fig. A.4 Distribution of $J$-integral estimated by line-integral along crack front of penny shaped crack subjected to unsymmetrical stress.

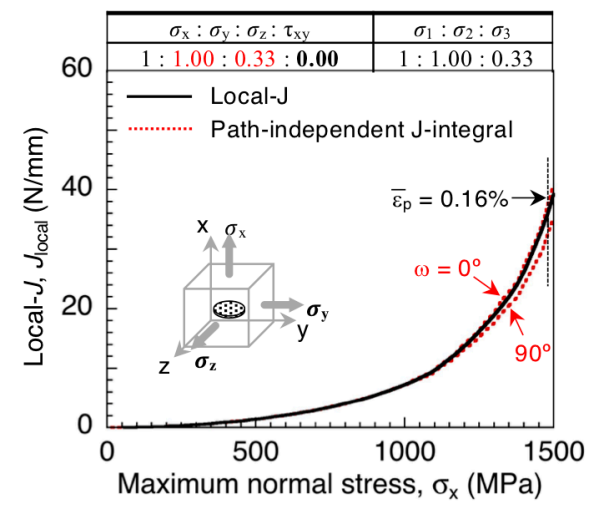

Fig. A.5 Comparison between Local- $J$ defined in this study and pathindependent $J$-integral for the unit cell subjected to unsymmetrical stress.

Suzuki: Fracture toughness measurement for fracture performance evaluation of weldments - significance of shallow notch ctod test, Welding International, 8-4 (1994), 279-285.

https://doi.org/10.1080/09507119409548590

2) S. Kaihara, T. Murayama, T. Kohno, F. Minani, M. Toyoda and K. Satoh: Applicability of Bending Critical CODs for Assessing Fracture Strength of Low-Temperature Service Steel Weldments, Quarterly Journal of The Japan Welding Society, 4-1 (1986), 176181. (in Japanese) https://doi.org/10.2207/qjjws.4.176

3) C. F. Shih and M. D. German: Requirements for a one parameter characterization of crack tip fields by the HRR singularity, International Journal of Fracture, 17 (1981), 27-43.

https://doi.org/10.1007/BF00043119

4) K. Satoh, M. Toyoda and K. Tanaka: Fracture Behaviors of SurfaceNotched Plate Subjected to Tension or Plate Bending, Journal of The Japan Welding Society, 50-8 (1981), 736-743. (in Japanese) https://doi.org/10.2207/qjjws1943.50.736

5) F. M. Beremin, A. Pineau, F. Mudry, J. C. Devaux, Y. D'Escatha and P. Ledermann: A local criterion for cleavage fracture of a nuclear pressure vessel steel, Metallurgical Transactions A, 14 (1983), 22772287.

https://doi.org/10.1007/BF02663302

6) F. Minami, T. Hashida, M. Toyoda, J. Morikawa, T. Ohmura, K. 
Arimochi and N. Konda: Dynamic Fracture Toughness Evaluation of Structural Steels Based on the Local Approach, Journal of the Society of Naval Architects of Japan, 1998-184 (1998), 453-464. (in Japanese)

https://doi.org/10.2534/jjasnaoe1968.1998.184_453

7) F. Minami and M. Ohata: Constraint Assessment of Brittle Fracture of Steel Components, ISO 27306 vs. FITNET FFS, Procedia Engineering, 10 (2011), 821-826. https://doi.org/https://doi.org/10.1016/j.proeng.2011.04.135

8) F. Minami, M. Ohata, H. Shimanuki, T. Handa, S. Igi, M. Kurihara, T Kawabata, Y. Yamashita, T. Tagawa and Y. Hagihara: Method of Constraint Loss Correction of CTOD Fracture Toughness for Fracture Assessment of Steel Components, Engineering Fracture Mechanics, 73-14 (2006), 1996-2020. https://doi.org/10.1016/j.engfracmech.2006.03.013

9) M. Ohata and F. Minami: Equivalent CTOD Ratio $\beta$ for Engineering Assessment of CTOD Correction for Constraint Loss, Journal of Pressure Vessel Technology, 134-5 (2012), 051403. https://doi.org/10.1115/1.4006346

10) B. R. Bass, W. J. McAfee, P. T. Williams and W. E. Pennell: Fracture assessment of shallow-flaw cruciform beams tested under uniaxial and biaxial loading conditions, Nuclear Engineering and Design, 188-3 (1999), 259-288.

https://doi.org/http://dx.doi.org/10.1016/S0029-5493(99)00035-7

11) ISO 27306:2009: Metallic materials — Method of constraint loss correction of CTOD fracture toughness for fracture assessment of steel components, (2009).

12) K. Shimizu, H. Shoji, T. Kato, H. Tanigawa and M. Ohata: Study on Fracture Modeling to Predict Brittle Fracture Resistance under Mixed Mode Loading, Quarterly Journal of The Japan Welding Society, 36-4 (2018), 274-284. (in Japanese) https://doi.org/10.2207/qjjws.36.274

13) ISO 12135:2002: Metallic materials - Unified method of test for the determination of quasistatic fracture toughness, (2002)

14) ASTM E1921-17a: Standard test method for determination of reference temperature $T_{0}$ for ferritic steels in the transition range, (2017).

15) X. Gao, C. Ruggieri and R. H. Dodds: Calibration of Weibull stress parameters using fracture toughness data, nternational Journal of Fracture, 92 (1998), 175-200.

https://doi.org/10.1023/A:1007521530191 